\title{
Fabrication of polyaniline coated conductive cotton for ammonia gas detection
}

\author{
Mon Myat Swe ${ }^{1}$, Tanthip Eamsa-ard ${ }^{1}$, and Teerakiat Kerdcharoen ${ }^{2, *}$ \\ ${ }^{1}$ Materials Science and Engineering Programme and Center of Nanoscience and Nanotechnology,Faculty of Science, Mahidol \\ University, Bangkok, Thailand \\ ${ }^{2}$ Department of Physics, Faculty of science, Mahidol University and NANOTEC Center of Excellence at Mahidol University, \\ National Nanotechnology Center, Bangkok, Thailand
}

\begin{abstract}
Nowadays, ammonia becomes major toxic pollutant. The industrial zones, agricultural zones and mining zones are facing this problem all over the world. Ammonia gives irritating strong smell in the environment and it can affect on the health of human with a long exposure time. Moreover, ammonia is also the biomarker which can indicate the health status of human. For these situations, many ammonia gas sensors are produced. In this work, flexible ammonia gas sensor is prepared based on polyaniline through in-situ polymerization process. We developed a wearable smart textile sensor for ammonia gas detection. $100 \%$ cotton which does not irritate the wearer was used for this sensor. The polyaniline-cotton composite was characterized by optical microscope, SEM and FTIR spectroscopy. The morphology of the composites reveal PANI was successfully coated on the cotton. The sensitivity of the gas sensors was monitored directly increasing the concentration of ammonia gas. The resistance changes of the sensors can be seen with increasing the concentration. It could also be proved that the sensor is flexible with bending test. In the future, this flexible PANI-cotton composite sensor can be used for ammonia detection in real applications.
\end{abstract}

\section{Introduction}

Ammonia $\left(\mathrm{NH}_{3}\right)$ is one of the major toxic pollutants while air pollution is the huge impact on the world today. Ammonia is widely used in chemicals, materials processing, refrigeration and fertilizers etc [1]. In chemical industry, ammonia is used as a main purpose for the production of nitric acid. Because of its ability to cool below $0^{\circ} \mathrm{C}$, almost all refrigeration facilities use in mechanical system and food processing make use of ammonia [2,3]. In agriculture sector, farms become to use a lot of fertilizers and animals manures rich of nitrogen based on compounds like ammonia for plant growth and higher yield of fruit and seed production. When fertilizer or manure is spread over the farmland, the smell of ammonia causes the farm very unpleasant smell [4]. Ammonia is the source for ammonium nitrate based on explosives used in mining operations and sodium cyanide $(\mathrm{NaCN})$ used in gold extraction from sulphide ores. On the other hand, creating a safe and cool environment for miners is one of the most important factors. For this reason, ice made by refrigeration is sent down the mine. In that way, the cold melt water is circulated through air cooler and provide cold environment [5].
The long terms exposure of ammonia can cause effect on our eyes, nose, mouth, lungs and throat. Our cardiac system and respiratory system can be damaged by the ammonia in the environment and it might lead to death [6-7]. For dangerous ammonia concentration, a detecting and warning alarm system should be applied in these industries [4].

Ammonia $\left(\mathrm{NH}_{3}\right)$ is considered to an important biomarker as it plays a significant role in human body $[8,9]$.

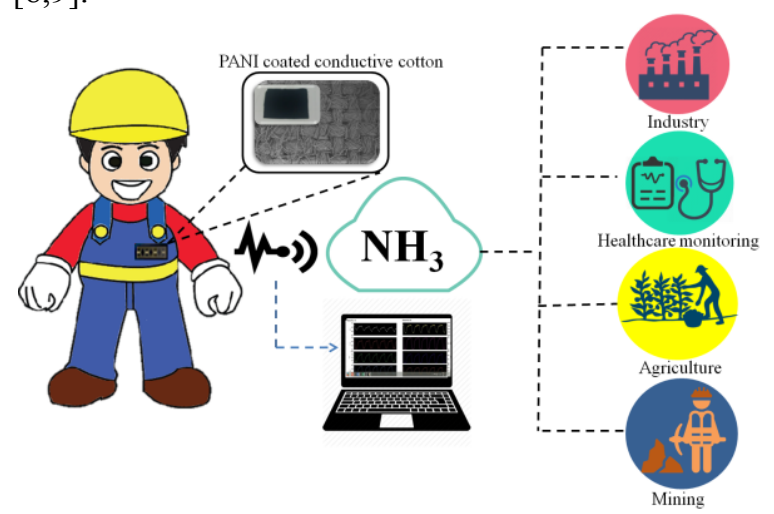

Fig. 1 Schematic diagram of application design for PANI coated conductive cotton as ammonia gas sensor 
Human body excretes ammonia in the form of urea and ammonium salt in urine, some ammonia through sweat glands and breath [10,11]. Patients with kidney failure and ulcers caused by Helicobacter pylori bacterial stomach infection have unbalanced ammonia in their urine and breath [12-14].

In order to detect ammonia $\left(\mathrm{NH}_{3}\right)$, sensors with great efficiency and quick response are required. Electronic textiles (e-textiles) can combine the functionality of smart electronic devices with the comfort and the flexibility of stylish clothing [15]. Polyaniline (PANI) is an extraordinary material to work as an active layer in gas sensing applications. Polyaniline (PANI) is the most appropriate conducting polymer for detecting ammonia $\left(\mathrm{NH}_{3}\right)$. Polyaniline (PANI) is the most appropriate conducting polymer for detecting ammonia $\left(\mathrm{NH}_{3}\right)$, due to its high conductivity, stability, easy synthesis, low cost and high reactivity with gases, such as ammonia [16]. In this work, it aims to fabricate conductive cotton based gas sensor for ammonia detection in industry, agriculture, mining and health care monitoring. Polyaniline (PANI) coated conductive cotton was prepared by in situ polymerization.

\section{Experimental}

\subsection{Reagents and Materials}

Aniline hydrochloride $97 \%$ was obtained from Aldrich, and used as received. Ammonium peroxydisulfate, analytical grade, from Ajax Finechem Pty Ltd; was used. Sodium hydroxide $(\mathrm{NaOH})$ was from RCL Labscan Limited. Undyed 100\% cotton was employed as substrates in the experiments.

\subsection{Preparation of PANI coated conductive cotton}

Fig. 2 shows the fabrication of PANI coated conductive cotton. $100 \%$ cotton was prepared into five different sample sizes $(1 \mathrm{cmx} 1 \mathrm{~cm}, 2 \mathrm{~cm} \times 2 \mathrm{~cm}, 3 \mathrm{cmx} 3 \mathrm{~cm}$, $4 \mathrm{~cm} \times 4 \mathrm{~cm}$ and $5 \mathrm{~cm} \times 5 \mathrm{~cm})$. The cotton samples were dipped in aqueous $5 \mathrm{M} \mathrm{NaOH}$ solution for 5 minutes for mercerizing, rinsed twice and dried before PANI coating.

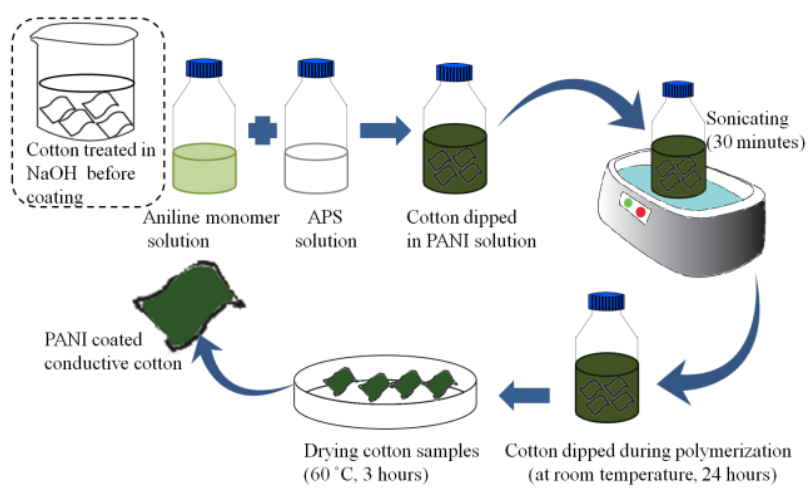

Fig. 2 Schematic diagram shows fabrication of PANI coated conductive cotton
PANI solution is made with monomer/oxidant molar ratio 1:2. Aniline hydrochloride (1.296 g) was dissolved in $50 \mathrm{~mL}$ DI water in a flask. Next, ammonium peroxydisulfate (APS) (2.738 g) was dissolved in $50 \mathrm{~mL}$ DI water. The solutions were mixed in a bottle and the cotton pieces were immersed in the mixed solution at that time. The mixture was sonicated for 30 minutes and left at room temperature for 24 hours to polymerize. After 24 hours, the cotton pieces were taken out of the solution and dried by heating in the oven at $60 \mathrm{C}$ for 3 hours

\section{Results and Discussions}

\subsection{Optical microscope}

Fig. 3 shows optical microscope images of PANI coated cotton with different lengths $(1 \mathrm{~cm}-5 \mathrm{~cm})$. It can be observed the interlaced structure of warp and weft yarn clearly from the low magnification version of optical microscope images.
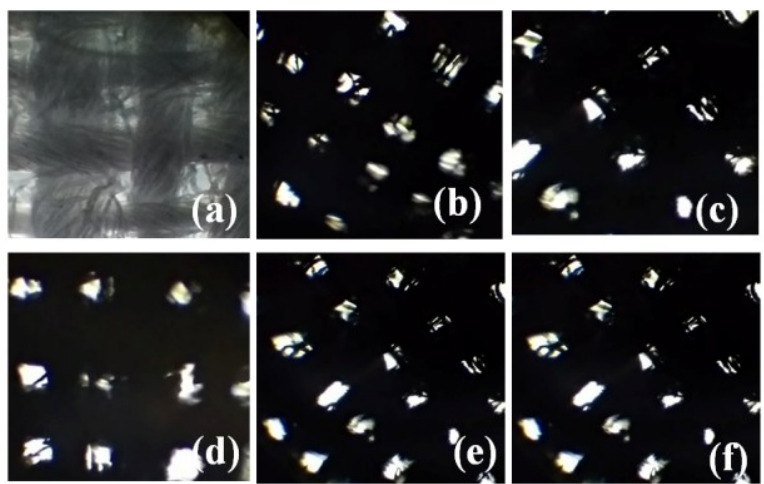

Fig. 3 Optical microscope images of (a) normal cotton and PANI coated conductive cotton (b) $1 \mathrm{~cm} \times 1 \mathrm{~cm}$ (c) $2 \mathrm{~cm} \times 2 \mathrm{~cm}$ (d) $3 \mathrm{~cm} \times 3 \mathrm{~cm}$ (e) $4 \mathrm{~cm} \times 4 \mathrm{~cm}$ (f) $5 \mathrm{~cm} \times 5 \mathrm{~cm}$

The deposited PANI causes the white cotton surfaces turned to dark green. Therefore, the polyaniline coated cotton in figure (b) to (f) tends to dark green colour indicating the well dispersion of PANI. It was shown that PANI can be successfully deposited on the cotton surface by in-situ chemical polymerization of aniline. Furthermore, polyaniline deposition process is the convenient way to reduce the surface hairiness of cotton as shown in the optical microscope images of PANI coated conductive cotton.

\subsection{Scanning Electron Microscope (SEM)}

The SEM images of the PANI coated cotton samples were taken at different magnifications with $100 \mathrm{X}$ (Fig. 4) and $1000 \mathrm{X}$ (Fig. 5). In SEM image of untreated cotton, it shows a very smooth surface. The presence of PANI can clearly be seen on PANI cotton. The non-smooth surface in figures shows evidently that PANI did not cover uniformly. It can still be seen non-uniform PANI coated areas although some areas of the fabric were fully coated. However, PANI perforation in the fabric yarn provided the cotton to be conductive. 


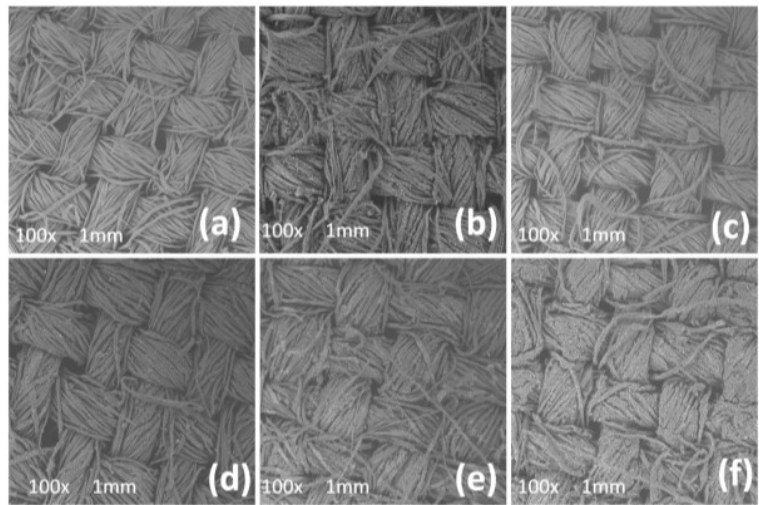

Fig. 4 Scanning Electron Microscope (SEM) images of (a) untreated cotton and PANI coated cotton (b) $1 \mathrm{cmx} 1 \mathrm{~cm}$ (c) $2 \mathrm{~cm} \times 2 \mathrm{~cm}$ (d) $3 \mathrm{~cm} \times 3 \mathrm{~cm}$ (e) $4 \mathrm{cmx} 4 \mathrm{~cm}$ (f) $5 \mathrm{~cm} \times 5 \mathrm{~cm}$

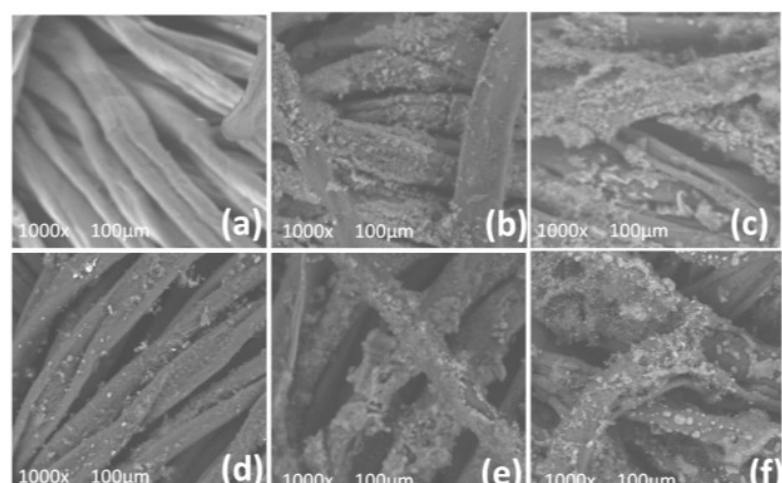

Fig. 5 Scanning Electron Microscope (SEM) images of (a) untreated cotton and PANI coated cotton (b) $1 \mathrm{cmx} 1 \mathrm{~cm}$ (c) $2 \mathrm{~cm} \times 2 \mathrm{~cm} \mathrm{(d)} 3 \mathrm{~cm} \times 3 \mathrm{~cm}$ (e) $4 \mathrm{~cm} \times 4 \mathrm{~cm}$ (f) $5 \mathrm{~cm} \times 5 \mathrm{~cm}$

\subsection{FTIR Spectroscopy}

The FTIR spectra for untreated cotton and PANI coated cotton with different ranges which were recorded in the range of $400-4000 \mathrm{~cm}^{-1}$ are shown in Fig.6. The peak at $3337.4 \mathrm{~cm}^{-1}$ in the spectrum of untreated cotton was characteristics of $\mathrm{CH}_{2}$ antisymmetric stretching vibrations of the secondary $\mathrm{CH}_{2} \mathrm{OH}$ groups present in the glucose units of cellulose[17]. At this area of spectra of PANI coated cotton samples, the absence of this peak may be due to the decreasing of secondary $\mathrm{CH} 2 \mathrm{OH}$ groups after PANI inclusion. At $2837.4 \mathrm{~cm}^{-1}$ of untreated cotton, the peak was $\mathrm{CH}_{2}$ symmetric stretching band.

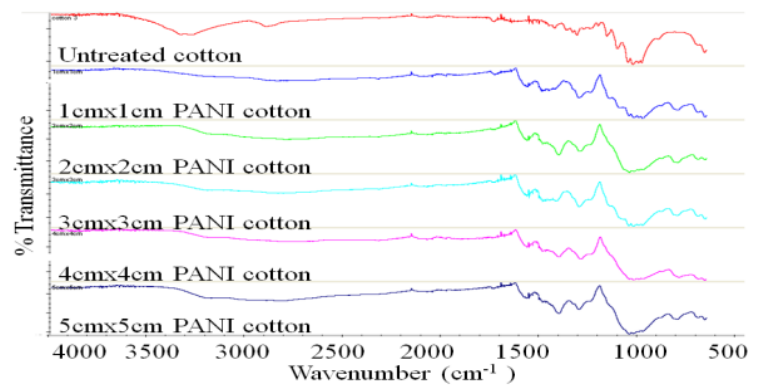

Fig. 6 FTIR spectra of untreated cotton and PANI treated cotton samples
The spectra of the PANI cotton with different ranges were the same as all of the samples were prepared under the same condition. The characteristic of PANI peaks were observed in the spectra of PANI coated cotton. The peak at $1403.9 \mathrm{~cm}^{-1}$ was attributed to the $\mathrm{C}=\mathrm{N}$ stretching modes of quinoid rings and $1305.1 \mathrm{~cm}^{-1}$ peak represented to the $\mathrm{C}-\mathrm{N}$ stretching of benzenoid rings. The $\mathrm{N}=\mathrm{Q}=\mathrm{N}$ stretching of the quinonoid units of PANI was observed at $1148 \mathrm{~cm}^{-1}$. This peak was due to electron delocalization. There was still small peaks in the PANI coated cotton spectra. It means that all of $\mathrm{CH}_{2} \mathrm{OH}$ groups in the glucose units of cellulose coud not interact completely with conductive PANI.

\subsection{Measuring the sensitivity of gas sensors}

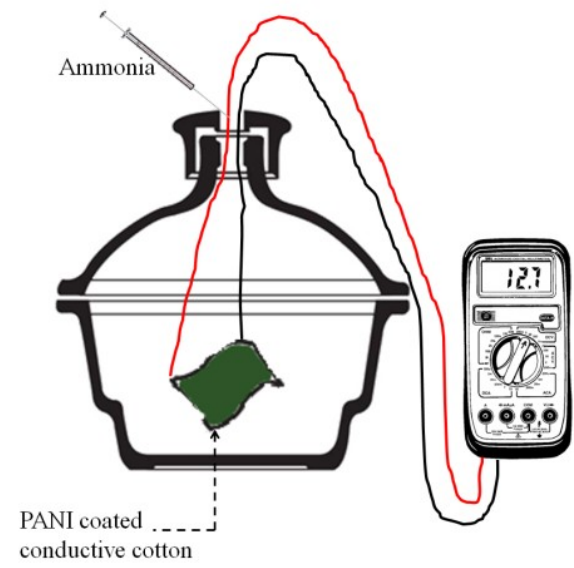

Fig. 7 Schematic measurement system for $\mathrm{NH}_{3}$ detection

For measuring gas sensors performance, the measurement system for $\mathrm{NH}_{3}$ gas detection is as shown in Fig. 7 The specially prepared gas chamber $(24000 \mathrm{~cm} 3)$ was used. The PANI coated cotton was put inside the gas chamber and the two edges of the cotton were attached with the clips of digital multimeter. In order to get the desired gas concentration for measuring, the measured amount of ammonia gas was injected with a syringe. The changing resistance values of the PANI coated cotton were monitored continuously using a digital multimeter.

Fig. 8 shows the sensitivity of PANI coated cotton gas sensor to ammonia gas from $25 \mathrm{ppm}$ to $100 \mathrm{ppm}$. The sensitivity of the composite gas sensor is defined as

$$
\% \mathrm{~S}=\left[\left(\mathrm{R}-\mathrm{R}_{0}\right) / \mathrm{R}_{0}\right] \times 100
$$

where $\mathrm{R}$ and $\mathrm{R}_{0}$ are the resistances of the sensor after and before VOCs exposure, respectively.

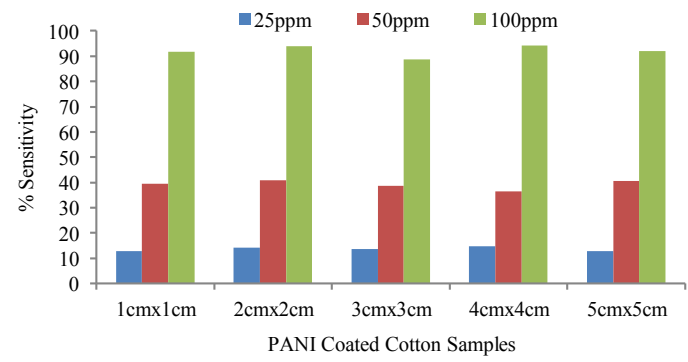

Fig. 8 The sensitivity of PANI coated cotton gas sensor 
The results reveal that the resistance values of PANI coated cotton changed according to the concentrations of the ammonia gas. The resistance increased with the increasing concentration (25ppm-100 ppm). However, the length of the cotton cannot affect on the sensitivity of the sensors. There is not too much difference in sensitivity of the PANI cotton with various lengths.

When the ammonia gas passes through the sensor,the interactions between the reactive sites of PANI and ammonia molecules occur. As ammonia has electron donating nature, it accepts hydrogen from PANI backbone and form ammonium ion. So, PANI looses $\mathrm{H}^{+}$ion and its electron density increases. In that way, the resistance of the gas sensors become increased.

\subsection{Flexibility Experiment}

Table I. The resistance of PANI coated cotton gas sensor sample in various condition.

\begin{tabular}{|c|c|c|c|}
\hline $\begin{array}{c}\text { Cotton } \\
\text { samples }\end{array}$ & Initial State & Bending & Normal \\
\hline $1 \mathrm{~cm} x 1 \mathrm{~cm}$ & $43 \mathrm{k} \Omega$ & $40 \mathrm{k} \Omega$ & $43 \mathrm{k} \Omega$ \\
\hline $2 \mathrm{~cm} \times 2 \mathrm{~cm}$ & $48 \mathrm{k} \Omega$ & $45 \mathrm{k} \Omega$ & $48 \mathrm{k} \Omega$ \\
\hline $3 \mathrm{~cm} \times 3 \mathrm{~cm}$ & $24 \mathrm{k} \Omega$ & $20 \mathrm{k} \Omega$ & $24 \mathrm{k} \Omega$ \\
\hline $4 \mathrm{~cm} \times 4 \mathrm{~cm}$ & $19 \mathrm{k} \Omega$ & $16 \mathrm{k} \Omega$ & $19 \mathrm{k} \Omega$ \\
\hline $5 \mathrm{~cm} \times 5 \mathrm{~cm}$ & $31 \mathrm{k} \Omega$ & $28 \mathrm{k} \Omega$ & $31 \mathrm{k} \Omega$ \\
\hline
\end{tabular}

\section{CONCLUSIONS}

PANI-cotton composite gas sensors have been successfully prepared with in-situ polymerization process. The morphology of the PANI-cotton showed that PANI can be successfully deposited on the cotton. The PANI based gas sensor can be operated efficiently at room temperature to detect ammonia with various concentrations. Varying the length of the cotton cannot affect on the sensing performance of the sensor. We hope that this wearable smart textile sensor will be very useful in real applications of ammonia gas detection in industry, agriculture and mining areas and for providing health status of the patients with kidney failure and stomach infection.

\section{ACKNOWLEDGMENT}

Mahidol University and National Nanotechnology Center are acknowledged.

\section{REFERENCES}

[1] M. Das, D. Sarkar, "One-pot synthesis of zinc oxide - polyaniline nanocomposite for fabrication of efficient room temperature ammonia gas sensor," Ceramics International, 43, pp. 1112311131, (2017).

[2] A.T. Bulgan, "Use of low-temperature energy sources in aquaammonia absorption refrigeration systems," Energy Conversion and Management, 38, pp. 1431-1438, (1997).
[3] P. Colonna, S. Gabrielli, "Industrial trigeneration using ammoniawater absorption refrigeration systems (AAR)," Applied Thermal Engineering, 23, pp. 381-396, (2003).

[4] B. Timmer, W. Olthuis, A. van den Berg, "Ammonia sensors and their applications - a review," Sensors and Actuators B, 107, pp. 666-677, (2005).

[5] J. Jermakka, L. Wendling, E. Sohlberg, H. Heinonen, E. Merta, J Laine-Ylijoki, T. Kaartinen, and U.M. Mroueh, "Nitrogen compounds at mines and quarries", VTT Technology, 225, (2012).

[6] T.R. Burns, S.D. Greenberg, M.L. Mace, J.A. Jachimczyk, "Pulmonary ultrastructure in acute ammonia toxicity in humans," Archives of Environmental \& Occupational Health, pp. 127-180, (1983).

[7] M. Caplin, "Ammonia-gas poisoning: forty-seven cases in a London shelter," The Lancet, pp. 95-96, (1941).

[8] S. Van de Velde, F. Nevens, P. Van hee, D. Steenberghe, "GCMS analysis of breath odor compounds in liver patients," Chromatography B, 875, pp. 344-348, (2008).

[9] S.J. Davies, P. Spanel, D. Smith, "Breath analysis of ammonia, volatile organic compounds and deuterated water vapor in chronic kidney disease and during dialysis," Bioanalysis 6, (2014).

[10] N.A. Campbell, J.B. Reece, "Biology," Pearson Education Inc., (2002).

[11] W. Ament, J.R. Huizenga, E. Kort, T.W.van der Mark, R.G. Grevink, G.J. Verkerke, "Respiratory ammonia output and blood ammonia concentration during incremental exercise," Sports Medicine, 20, pp. 71-77, (1999).

[12] L.R. Narasimhan, W. Goodman, C. Kumar, N. Patel, "Correlation of breath ammonia with blood urea nitrogen and creatine duringhemodialysis," Proceedings of the National Academy of Sciences of the United States, 8, pp. 4617-4621, (2001).

[13] B. Marshall, J.R. Warren, "Unidentified curved bacillus and gastric epithelium in active chronic gastritis," The Lancet, $\mathbf{1}$, pp. 1273-1275, (1993).

[14] D.J. Kearney, T. Hubbard, D. Putnam, "Breath ammonia measurement inHelicobacter pyloriinfection," Digestive Diseases and Sciences, 47, pp. 2523-2530, (2002).

[15] T. Seesaard, P. Lorwongtragool, S. Season, T. Kerdcharoen, "A novel creation of thread-based ammonia gas sensors for wearable wireless security system," International Conference on Electrical Engineering/Electronics, Computer, Telecommunications and Information Technology (ECTI-CON), IEEE, (2014).

[16] A. Kukla, Y. Shirshov, S. Piletsky, "Ammonia sensors based on sensitive polyaniline films," Sensors and Actuators B, 37 pp. 135-140, (1996).

[17] R.T. O'Connor, "Instrumental Analysis of Cotton Cellu-lose and Modified Cellulose,” Marcel Dekker, Newyork, (1972). 